Revista de Negócios_ISSN 1980.4431_vol. 19, n. 2, p. 3_20, 2014_DOI:10.7867/1980431.2014v19n2p3_20

\title{
As interfaces entre estratégia e ambiente institucional de referência: o caso do Tribunal Regional Eleitoral de Santa Catarina (TRESC)
}

\section{The interfaces between strategy and institutional environment of reference: the case of the Regional Electoral Court of Santa Catarina (TRESC)}

Carlos Eduardo Justen

UFSC Universidade Federal de Santa Catarina - Brasil

justencarlos@gmail.com

Luís Moretto Neto

UFSC Universidade Federal de Santa Catarina - Brasil

moretto@cse.ufsc.br

Recebido em 06 de junho de 2013. Alterado em 10 de agosto de 2013. Aprovado em 14 de agosto de 2013

Editor Responsável: Edson Roberto Scharf, Dr.

Processo de avaliação por double blind review

\begin{abstract}
Resumo
O presente artigo trata da interface entre as transações da organização com o ambiente e as respectivas estratégias delineadas, inserindo-se no contexto de alargamento das investigações empíricas sobre o novo institucionalismo sociológico e sua potencial aplicação ao campo dos estudos em estratégia. A partir de um estudo de caso, de cunho qualitativo, examinou-se a influência do ambiente institucional de referência no direcionamento estratégico do Tribunal Regional Eleitoral de Santa Catarina (TRESC), formalizado no processo de planejamento estratégico, adotando-se três categorias analítico-empíricas - base estratégica corporativa, agentes externos e campo organizacional. $\mathrm{O}$ delineamento da pesquisa foi duplamente amparado, do ponto de vista teórico, por discussões precedentes acerca da noção de ambiente institucional, no contexto do corpus conceitual do novo institucionalismo sociológico, e da noção de estratégia como processo institucionalmente condicionado, numa abordagem construtivista da estratégica. Como resultado, percebeu-se que a lógica de ação institucional envolveu a procura por
\end{abstract}

legitimidade, aceitação e credibilidade junto ao campo organizacional e à sociedade, numa trajetória conservadora, atrelada à concentração em competência técnico-instrumental, com o foco nas eleições e centralização nos processos tecnológicos de registro, apuração e totalização dos votos. Em decorrência, a adaptabilidade e as mudanças necessárias no longo prazo, como a atuação na conscientização política e nos processos deliberativos e dialógicos que fogem ao âmbito político-eleitoral, foram desconsideradas. Desta feita, os elementos institucionais presentes no campo da organização em tela, ao preservarem a sobrevivência da organização num horizonte temporal próximo, podem dificultar a adaptabilidade e as mudanças necessárias no longo prazo, impactando na efetividade do serviço prestado à população.

Palavras-chave: Ambiente Institucional. Estratégia. Legitimidade. Planejamento Estratégico. Novo Institucionalismo Sociológico.

\section{Abstract}

This article deals with the interface between the 
organization's transactions with the environment and their strategies outlined, by inserting it in the context of enlargement of the empirical research on the new sociological institutionalism and its potential application to the field of studies in strategy. From a case study, a qualitative, we examined the influence of the institutional environment reference in the strategic direction of the Regional Electoral Court of Santa Catarina (TRESC), formalized in the strategic planning process, adopting three categories-analytic empirical - based corporate strategy, external agents and the organizational field. The study design was double-backed, the theoretical point of view, for previous discussions about the notion of institutional environment in the context of conceptual corpus of the new sociological institutionalism, and the notion of strategy as a process institutionally conditioning, a constructivist approach to strategic. As a result, it was realized that the logic of institutional action involved the search for legitimacy, acceptance and credibility in the organizational field and society in a conservative way, linked to the concentration of technical-instrumental, with a focus on elections and centralization in technological processes of registration, calculation and aggregation of votes. As a result, adaptability and changes needed in the long term as the acting political awareness and the dialogic and deliberative processes that are beyond the scope of electoral politics, have been disregarded. This time, the elements present in the field of institutional organization screen to preserve the organization's survival in a near horizon, may hinder the adaptability and the changes needed in the long term, impacting the effectiveness of the service provided to the population.

Keywords: Institutional Environment. Strategy. Legitimacy. Strategic Planning. New Sociological Institutionalism.

\section{Introdução}

As abordagens institucionalistas nos estudos organizacionais ${ }^{i}$ vêm merecendo progressiva atenção por parte da academia brasileira. Esse recente destaque, não obstante alguns desenvolvimentos no plano da discussão teórica, carece de maior amplitude e aprofundamento no plano da pesquisa empírica, a qual restringe-se, em grande medida, nos fenômenos do isomorfismo e do decoupling ${ }^{\mathrm{ii}}$ (KIRSCHBAUM; CRUBELLATE, 2009), das estratégias de legitimação e dos processos de institucionalização de campos organizacionais (CARVALHO; VIEIRA;
GOULART, 2005). O presente artigo insere-se no contexto de alargamento das investigações empíricas, tratando da interface entre as transações da organização com $\mathrm{o}$ ambiente $\mathrm{e}$ as respectivas estratégias delineadas.

$\mathrm{O}$ institucionalismo nos estudos organizacionais, de matiz claramente sociológico (DIMAGGIO; POWELL, 1991), contrapôs-se, marcadamente a partir de Selznick e seu estudo sobre a Tennessee Valley Authority (TVA), à narrativa racionalista então recorrente que concebia a organização como um instrumento direcionado para a resolução de problemas coletivos, seja de ordem social, como visto na denominada Escola de Relações Humanas, seja de gestão, algo caro aos especialistas da Escola Clássica.

$\mathrm{Na}$ perspectiva dessa narrativa, todas as condicionantes sociais, políticas e institucionais que afetavam as organizações eram passíveis de conversão em problemas de engenharia, solúveis mediante intervenção técnica. Era, de fato, uma teoria universalizante, alicerçada no sistema de mercado e na racionalidade da eficiência (CLEGG, 1998). A abordagem institucional ampliou o horizonte da compreensão do fenômeno organizacional, ao destacar as características sociológicas que lhe são particulares e que não se apegam apenas ao interesse por racionalidade instrumental ou eficiência econômica.

De maneira geral, três são as principais contribuições das abordagens institucionais aos estudos organizacionais: (i) o reconhecimento de relações tanto de dependência quanto de autonomia relativa frente ao ambiente em que a organização está inserida, contrapondo-se às perspectivas unidirecionais que apenas concebiam a adaptação da organização ao ambiente e vice-versa; (ii) a introdução de arcabouços conceituais e teóricos tendentes a considerar elementos e explicações cognitivas e culturais; e, nesse sentido, (iii) a compreensão dos quadros de valores culturais e institucionais do ambiente 
particular no qual a organização está situada, o que trouxe uma nova concepção de ambiente.

Essa redefinição do conceito de ambiente organizacional envolve a inclusão de elementos simbólicos, tanto na constituição quanto na interpretação do ambiente como variável organizacional. Com isto, fica consolidada a noção elementar de que a organização está embebida num contexto formado por crenças e valores, representativos à semelhança, ou mesmo em intensidade maior, dos requisitos técnicos e eficientes ligados aos valores de troca que orientam o mercado. Reconhece-se assim a influência do contexto institucional de referência no que toca à performance organizacional e ao processo de decisão estratégica.

Esse reconhecimento, como afirma Fonseca (2003), pode ser explorado para o enriquecimento de estudos em mudança e estratégia organizacional. A lógica subjacente é a de que a análise da estratégia é "condicionada pela relação entre instituição, interpretação e ação dos atores sociais significativos em cada situação espaciotemporalmente delimitada" (MACHADO-DA-SILVA; VIZEU, 2007, p. 91).

A organização, portanto, nas transações que efetua com o ambiente específico em que está inserida, ao interpretar, agir e reagir frente às demandas técnicas e subjetivas (diretrizes normativas, crenças, mitos, símbolos), estabelece regras e procedimentos considerados legítimos, utilizados para fins de sobrevivência (MACHADO-DASILVA; FONSECA; FERNANDES, 1998). A busca de legitimidade, que, por sua vez, garantirá estabilidade e sobrevivência, conduzirá a um processo de homogeneização, de isomorfismo institucional, acarretando uma compatibilidade e convergência crescente das organizações entre si e de cada uma delas com as características ambientais. Desta feita, a conformidade a valores e normas sociais, em determinados contextos com maior influência do que a performance técnica, vincula o desempenho ou a trajetória de uma organização ou de um grupo de organizações.

A associação entre valores e normas sociais, que compõem o ambiente institucional, e a trajetória da organização constituirá o objeto analítico deste estudo. A organização estudada é o Tribunal Regional Eleitoral de Santa Catarina (TRESC), órgão do Poder Judiciário Federal, integrante do campo organizacional da Justiça Eleitoral, que passa por um processo de reavaliação de seu direcionamento estratégico, mediante a implantação de processo de planejamento estratégico.

O objetivo do estudo, portanto, pode ser sintetizado na investigação da influência do ambiente institucional de referência no direcionamento estratégico do TRESC, a partir da seguinte problemática de pesquisa - quais as influências do ambiente institucional de referência para o direcionamento estratégico da organização investigada e de que forma tal relacionamento condiciona o futuro dessa organização?

Para tanto, será feito uso, do ponto de vista teórico-analítico, do novo institucionalismo sociológico, especialmente da noção de ambiente institucional de referência, e da noção de estratégia como fenômeno social e institucionalmente construído. Como hipótese de pesquisa, considera-se que, ao desenvolver o processo de direcionamento estratégico, uma organização, em busca de legitimidade no campo organizacional de referência, adota os valores e as normas sociais ali presentes, numa escolha condicionada pelos elementos institucionais que, ao desconsiderarem escolhas estratégicas que vão de encontro aos referenciais do ambiente institucional, visam à estabilidade do desempenho e da trajetória organizacional.

Especificamente para a organização 
investigada, a relevância do presente estudo reside na possibilidade de refletir acerca de suas escolhas estratégicas de longo prazo e de adotar decisões gerenciais mais coerentes com os clamores sociais da aplicação eficiente dos recursos públicos e da prestação otimizada de serviços demandados pela coletividade, em relação de aproximação entre Estado e sociedade civil, na qual a preocupação primária deixe de estar voltada à manutenção da estrutura burocrática. Do ponto de vista acadêmico, o estudo representa esforço de alargamento das investigações empíricas que adotam a abordagem institucionalista nos estudos organizacionais, trazendo, ademais, reflexões acerca da relação entre ambiente e estratégia organizacional.

Nesse diapasão, o presente artigo está estruturado nas seguintes seções: (a) a discussão conceitual dos principais aspectos da abordagem institucional relacionados ao caso analisado, bem como da perspectiva de estratégia correspondente; (b) a delimitação metodológica do estudo; (c) a discussão do caso investigado; e (d) as considerações finais.

\section{A noção de ambiente institucional}

Até a década de 70, o institucionalismo nos estudos organizacionais, especialmente a partir das contribuições de Phillip Selznick, estava fortemente ligado a perspectiva estruturalfuncionalista em torno de duas premissas fundamentais: primeiro, os componentes estruturais de um sistema devem atuar de forma integrada com o fito de sobrevivência individual e sistêmica, sendo que a modificação em um componente requer mudanças em outros elementos da espécie; segundo, as estruturas existentes contribuem para o funcionamento de um sistema social, no mínimo, para a manutenção de seu equilíbrio (ZUCKER; TOLBERT, 2004).

A modificação precípua é trazida por Meyer e Rowan (1977), em trabalho no qual defendem que as estruturas formais, concomitantemente, geram tanto ações (objetivas) como propriedades simbólicas (subjetivas). A estrutura, portanto, não se reflete somente como resposta a condicionantes ambientais de eficiência, mas também em razão de exigências sociais (CARVALHO; VIEIRA; GOULART, 2005). Essa abordagem institucional alternativa, que mantém estrita preocupação com temas ambientais, possui centro na forma pela qual as práticas e padrões são valorizados e estruturas e interações são legitimadas.

Segundo Scott (1992), a contribuição mais importante na pesquisa sobre ambiente como variável organizacional está na inclusão de elementos simbólicos na formação dos ambientes organizacionais, contribuição levada a cabo pelos institucionalistas (CARVALHO; VIEIRA; LOPES, 1999). Todavia, como observam Tolbert e Zucker (2004), o insight de que as organizações eram constituídas de aspectos simbólicos não se fazia totalmente novo. $\mathrm{O}$ pioneirismo, especialmente de Meyer e Rowan, está no reconhecimento e na tentativa de explicação do uso da estrutura formal para fins simbólicos.

Assim, a adoção da estrutura formal poderia ocorrer sem relação com aspectos de coordenação e controle. Com isso, a atenção é direcionada para aspectos externos não relacionados ao processo de produção e passa-se a questionar a importância de características estruturais como tamanho e tecnologia. Ademais, a avaliação social das organizações e sua sobrevivência poderiam estar na observação da estrutura formal e não nos resultados tangíveis de desempenho de tarefas. A premissa de que organizações tecnicamente ineficientes seriam cabalmente defenestradas do "mercado" por intermédio da competição passou a ser motivo de contestação.

$\mathrm{Na}$ visão de Meyer e Rowan (1977), as organizações não se estruturam unicamente com o intento de preencher os requisitos técnicos, mas em razão também de seus efeitos simbólicos. Assim, as orga- 
nizações respondem as exigências do ambiente que a circunda, como já pacificado na teoria das organizações: a principal diferença, contudo, reside no fato de que a resposta tem como origem não apenas variáveis objetivas (tecnologia, tamanho, dentre outras), mas da mesma forma e, em certos casos, com maior reforço, crenças, valores e mitos compartilhados (CARVALHO; VIEIRA; GOULART, 2005).

Inclusive, como atesta Carvalho (2000), as estruturas organizacionais que, por suas características específicas, sejam bastante sensíveis aos respectivos ambientes institucionais, parecem reproduzir, significativamente, os valores do ambiente em detrimento das demandas técnicas de sua área de especialização. Desta feita, a noção de ambiente perpassa a simples fonte e destino de recursos materiais, adquirindo status de fonte e destino de recursos simbólicos, em especial reconhecimento simbólico e legitimação. A sobrevivência das organizações passa a estar fundamentada na eficiência conseguida no ambiente técnico e na legitimidade alcançada no ambiente institucional (SILVA; OLIVEIRA, 2008; CARVALHO; VIEIRA; LOPES, 1999).

Abandonando a premissa de um ambiente formado somente de recursos técnicos, e dando o adequado tratamento aos recursos simbólicos, fica implícito o aceite de que a concorrência por recursos e clientes (lógica de mercado) "enfrenta a competição" do alcance de legitimidade institucional e de aceitação social. Neste sentido, válido o registro de que a função de provedor de recursos técnicos - ambiente técnico - não deve ser subvalorizada; apenas é alargado o conceito de ambiente para inclusão de uma camada simbólica à sua análise - ambiente institucional (CARVALHO, 2000).

O ambiente técnico envolve o intercâmbio de produtos e serviços e a avaliação pelo controle racional do processo de produção, enquanto que o ambiente institucional abrange a elaboração e a conformidade a normas e exigências subjetivas, além da avaliação da adequação da organização a esse estrato simbólico (SCOTT, 1992; MEYER; ROWAN, 1977). Assim, enquanto o ambiente técnico envolve tecnologias e trocas de produtos e serviços, cujo critério de sobrevivência é a eficiência e a efetividade, $\mathrm{o}$ ambiente institucional engloba regras e valores socialmente aceitos a partir do estabelecimento de estruturas e processos corretos. O critério norteador da sobrevivência, in casu, é a conformidade (PACHECO, 2001).

Como bem aponta Carvalho (2000, p. 4), "a eficiência, a produção de bens e serviços para o mercado e a concorrência são elementos que compõem a racionalidade própria de um ambiente técnico, onde o principal objetivo é realizar sua produção no mercado", enquanto "[...] a legitimidade, a aceitação social e a credibilidade junto à sociedade são elementos que constroem a racionalidade de uma organização subordinada a um ambiente institucional" (p. 4).

$\mathrm{Na}$ perspectiva do ambiente técnico, as organizações direcionam seu foco a questões de âmbito econômico, intentando reduzir incertezas mediante a eficiente operação produtiva e de alocação de recursos. Como contraponto, sob a égide do ambiente institucional, a sobrevivência da organização está atrelada à adequabilidade e ao isomorfismo. Os mecanismos de controle ambiental passam a ser regras, inspeções e regulamentações (PACHECO, 2001).

Neste sentido, para a abordagem institucional, a organização, em busca de legitimidade e recursos, em suma, de sobrevivência, conforma sua estrutura e sua estratégia com os padrões institucionais de um ambiente de referência - campo organizacional -, de forma que ocorra redução de incertezas e justificativa para o desenvolvimento de suas atividades. A institucionalização, isto é, o processo pelo qual condutas e obrigações sociais passam a 
consistir em regra no pensamento e ação sociais (MEYER; SCOTT, 1983), ocorre de maneira progressiva: primeiro, ações cotidianas tornam-se tipos, categorias; após, no decorrer dos tempos, passam a tornar-se dogmas, incluindo-se no sistema de conhecimento humano em caráter normativo (MACHADO-DA-SILVA et al., 2003). A finalidade primeira, na linha da sociologia do conhecimento de Berger e Luckmann (2009), é a criação e reprodução de grupos sociais duradouros.

$\mathrm{O}$ processo de institucionalização tem locus e consequência. O locus, como já dito, é a noção de campo organizacional, entendida como "aquelas organizações que, em conjunto, constituem uma área reconhecida da vida institucional: fornecedores-chave, consumidores de recursos e produtos, agências regulatórias e outras organizações que produzam serviços e produtos similares" (DIMAGGIO; POWELL, 2005, p. 76). Seu uso é associado à idéia de que as organizações garantem sobrevivência ao compartilharem valores em certo espaço social, o que implica dizer que o "desempenho ou a trajetória de uma organização, ou de um grupo de organizações, estão vinculados às diretrizes normativas e valorativas dadas por atores externos, que se inserem nos diferentes níveis das organizações, afetando sua política e estrutura" (CARVALHO; VIEIRA, 2003, p. 12).

O conceito de campo organizacional, assim vislumbrado, contém tanto um componente relacional quanto estruturas institucionais segundo um processo de estruturação que levará ao isomorfismo organizacional - a consequência. Segundo DiMaggio e Powell (2005), os campos organizacionais, após estruturados, fornecem aos que neles interagem um contexto em que os métodos racionais em lidar com a incerteza ambiental e as restrições daí decorrentes levam à homogeneidade em termos de estrutura, cultura e resultados.

Assim como a distinção ambiente técnico/institucional, o isomorfismo apresenta duas nuances: a competitiva, identifi- cada em ambientes marcados pela competição livre e aberta, sendo foco de análise da ecologia populacional; e a institucional, campo de atuação dos institucionalistas sociológicos, base para a compreensão do simbolismo e do cerimonial latentes nas organizações hodiernas, com premissa na compatibilidade crescente das organizações com as características ambientais (DIMAGGIO; POWELL, 2005).

Tal compatibilidade é decorrência da atuação de quatro mecanismos isomórficos. O isomorfismo coercitivo é fruto de pressões externas, formais e informais, emanadas de outras organizações (relação de dependência) e da sociedade em geral, materializando-se na força, na persuasão e no convite. No Brasil, sua dominância é justificada pela forte tradição patrimonialista e pelo processo de formação sóciocultural brasileiro. O isomorfismo mimético traduz-se em resposta padronizada à incerteza. Assim, buscam-se modelos, práticas e procedimentos já testados ou experimentados alhures diante da incerteza ou ambiguidade na adoção de solução sui generis. O mimetismo é, em termos relativos, vantajoso para a organização, devido ao baixo custo e ao maior comprometimento dos dirigentes na implementação da mudança. É o que Richard Cyert e James March, em Behavioral theory of the firm, chamam de tendência a evitar incertezas. O isomorfismo normativo, por sua vez, é associado à profissionalização, às pressões normativas devido a um senso de obrigação ou dever (base moral) para com altos padrões de desempenho, ditado por normas profissionais. O isomorfismo indutivo, por fim, é vinculado a incentivos financeiros indiretos, na forma de isenções ou remições fiscais, ou mesmo promessa de algum incentivo ou privilégio futuro (DIMAGGIO; POWELL, 2005; PECI, 2006; PACHECO, 2001; MACHADO-DA-SILVA; GONÇALVES, 2004; MOTTA; VASCONCELOS, 2002; DAFT, 2006).

$\mathrm{O}$ isomorfismo institucional acarreta substanciais consequiências no âmbito organizacional, visto que: 
(a) elas [as organizações] incorporam elementos que são legitimados externamente, dando menos importância à eficiência; (b) empregam critérios cerimoniosos ou externos para definir os valores dos elementos estruturais; e (c) dependem de instituições externamente legitimadas, aumentando o comprometimento dos participantes internos e beneficiários (MEYER; ROWAN, 1980, p. 30 apud PACHECO, 2001, p. 6).

Assim, muito mais do que competir, as organizações buscam a cooperação, não apenas com suas congêneres, mas também com os demais interessados e com a sociedade como um todo, pois é do adequado gerenciamento da rede de dependência que a organização consegue tornar-se legítima e, por conseguinte, sobreviver.

\section{Estratégia como construção instituci- onalmente condicionada}

A concepção da estratégia como um processo construtivista institucionalmente condicionado implica a crítica de outra noção, determinista ou objetiva, identificada com uma visão de ambiente como elemento objetivo, determinado por forças impessoais (VASCONCELOS, 2004), e uma interpretação de estratégia como fruto da racionalidade $\mathrm{e}$ da intencionalidade dos decisores organizacionais (CRUBELLATE; GRAVE; MENDES, 2004), obcecados pela mensuração e pelas generalizações estatísticas (HAFSI; MARTINET, 2008).

A perspectiva construtivista de estratégia, por sua vez, baseada na sociologia do conhecimento de Berger e Luckmann (2009) - o conhecimento é concomitantemente produto e fator de mudança social -, traz em seu bojo a premissa de que a estratégia só pode ser concebida no seu contexto de ação, "que resulta da construção so- cial das relações entre ambiente e organização" (VASCONCELOS, 2004, p. 165).

As implicações de tal perspectiva em estratégia organizacional, no entendimento de Vasconcelos (2004), são de grande vulto, haja vista: (a) o abandono da premissa de que a relação ambienteorganização é de mão única, cabendo à organização o papel reativo; (b) a revisão de oportunidades, ameaças e restrições; (c) um repensar do papel da estratégia, a partir dos processos de tomada de decisão. Tais implicações, outrossim, estendem-se ao campo da pesquisa acadêmica em estratégia, porquanto deslocam o foco epistemológico das relações de causa-efeito para o processo de interpretação e atribuição de sentido e suas consequiências.

Desse modo, a relação produtomercado é secundária. Passa a receber importância aspectos vinculados ao processo de tomada de decisão, como valores e símbolos, linguagem e interpretações (VASCONCELOS, 2004). O ambiente, majoritariamente simbólico, é visto como a representação construída pelas crenças institucionais, influenciada reciprocamente pelas ações tomadas a partir de sua interpretação.

De acordo com Machado-da-Silva e Fonseca (2002, p. 92), a própria essência do fenômeno da estratégia impõe que, além do pressuposto racional-instrumental, avente-se "a influência na ação dos sistemas de significados objetivos e externos ao indivíduo", algo que pode ser imputado à abordagem institucional.

A estratégia, assim, passa a ser condicionada pela imbricada relação entre instituição, interpretação e ação de atores sociais (organizações), dados contexto e tempo definidos (MACHADO-DASILVA; VIZEU, 2007). O pensamento estratégico, como decorrência, surge da imersão social dos atores institucionais, que, por sua vez, é condicionada por padrões (coercitivos, miméticos, normativos, indutivos) predominantes naquele campo 
organizacional (CRUBELLATE, GRAVE; MENDES, 2004).

Compreendida assim, como alertam Machado-da-Silva e Fonseca (2002), a ação estratégica resume-se, embora nem sempre, em aprovação. Na dinâmica organizacional, há confronto de alternativas de ação, mas estas tanto quanto os cursos de ação são definidos com base em critérios de referência avalizados por estruturas e sistemas sociais.

Dito de outra forma, o comportamento organizacional é canalizado por padrões criados e compartilhados nas diversas interações entre congêneres e incorporados na forma de normas e regras objetivas, legitimadas pela sociedade em geral como a maneira mais eficaz de agir (MACHADO-DA-SILVA; FONSECA, 2002). $O$ processo organizacional resultante dessa legitimação - isomorfismo institucional - é refletido no fato de que elaboração e escolha estratégica seguem padrões institucionalizados no ambiente de natureza coercitiva, mimética, normativa e indutiva (CRUBELLATE; GRAVE; MENDES, 2004). O agente organizacional decide racionalmente; contudo, trata-se de uma racionalidade limitadas pelos padrões mencionados.

Do ponto de vista da concorrência por recursos, sejam técnicos ou institucionais, a organização fundamenta suas estratégias a partir do gerenciamento da imagem institucional, buscando legitimidade. A procura resulta em homogeneidade do conhecimento e interpretação da realidade. Disto, por sua vez, resulta não apenas conformidade na formulação de estratégia, mas também nas formas estruturais e características processuais (MACHADODA-SILVA; BARBOSA, 2002). O isomorfismo estratégico concretiza-se em uma homogeneidade de escolhas estratégicas, da qual resultam padrões estratégicos semelhantes em organizações atuantes no mesmo campo organizacional (GIMENEZ; JUNIOR; GRAVE, 2007).

O planejamento estratégico, modelo mais representativo da difusão e institucio- nalização das práticas formais de estratégia, tem papel relevante no contexto de homogeneização de práticas, estruturas e procedimentos. Seu valor significativo, enaltece-se, está no uso como instrumento de formalização de estratégias. A formalização, em conjunto com as práticas de emulação (benchmarking) e com as necessidades de conformidade às expectativas internas e externas, faz do planejamento estratégico um potencial elemento isomórfico, por intermédio de, no mínimo, três recursos simbólicos.

O primeiro materializa-se na cooptação de um consultor externo e de seu ferramental metodológico - o consultor possui dois papéis fundamentais: legitimar o esforço de implantação perante os atores organizacionais e trazer insights, práticas e procedimentos de outras organizações reputadas como as de vanguarda no contexto de um dado campo organizacional. $\mathrm{O}$ segundo concretiza-se no atendimento e na influência dos padrões e convenções profissionais predominantes dentre os atores e no campo organizacional, isto é, a cooptação da lógica profissional (com as regras de conduta, técnicas e procedimentos) predominante no processo de planejamento estratégico. $\mathrm{O}$ terceiro, por fim, na iniciativa e no desenvolvimento (mesmo que a mera tentativa ou manobra para tanto) do próprio planejamento estratégico como instrumento para a obtenção de prestígio e de reconhecimento dentro do campo organizacional.

Esses recursos isomórficos, em conjunto com a adequação da organização ao ambiente institucional de referência, refletem no processo de construção da estratégia e, por conseguinte, no direcionamento estratégico da organização, algo que será investigado no caso analisado neste artigo. Nele, em particular, confirmando a hipótese aventada para o estudo, evidenciase a opção por um curso de ação já legitimado pelo campo organizacional de referência, o que implica a desconsideração ou subavaliação do potencial de alternativas estratégicas contrárias aos elementos sub- 
jetivos dominantes, os quais, ao permitirem a sobrevivência da organização e das relações de poder vigentes para o curto e médio prazo, podem dificultar as mudanças necessárias ao enfrentamento de mudanças ambientais futuras.

\section{Procedimentos metodológicos}

O presente estudo, delineado como de caso (STAKE, 2005), de abordagem qualitativa, consiste no exame da influência do ambiente institucional de referência no direcionamento estratégico do Tribunal Regional Eleitoral de Santa Catarina (TRESC), órgão do Poder Judiciário Federal. O processo investigado, na construção da estratégia organizacional, foi o planejamento estratégico desenvol- vido pelo órgão público analisado.

Os dados foram coletados por intermédio de entrevistas semi-estruturadas, realizadas junto a informantes-chaves, selecionados por sua importância em relação à implantação e ao desenvolvimento do processo de planejamento estratégico (vide Quadro 1); de observação participante, mediante participação de um dos autores do estudo na equipe gestora do planejamento estratégico; da consulta a documentos internos da instituição analisada, tais como relatórios de atividades, mensagens eletrônicas, atas de reunião, relatos documentados e fluxogramas; bem como de documentos organizacionais e/ou relativos à organização, de âmbito e divulgação externos.

Quadro 1 - Discriminação do processo de coleta de dados.

\begin{tabular}{|l|l|}
\hline \multicolumn{2}{|c|}{ Dados primários da pesquisa } \\
\hline Instrumento de coleta de dados & Entrevista semi-estruturada \\
\hline Atores entrevistados & $\begin{array}{l}\text { Diretor-Geral e Assessor de Planejamento e Gestão } \\
\text { Estratégica }\end{array}$ \\
\hline Elementos estruturantes da entrevista & Categorias analítico-empíricas apontadas no Quadro 2 \\
\hline \multicolumn{1}{|c|}{ Dados secundários da pesquisa } \\
\hline Fontes dos dados & $\begin{array}{l}\text { relatórios de atividades, mensagens eletrônicas, atas de } \\
\text { reunião e fluxogramas (âmbito interno) / sítio eletrônico } \\
\text { na rede mundial de computadores (âmbito externo) }\end{array}$ \\
\hline Elementos estruturantes da coleta & Categorias analítico-empíricas apontadas no Quadro 2 \\
\hline
\end{tabular}

Fonte: elaborada pelos autores (2012).

As categorias analítico-empíricas e as variáveis utilizadas na pesquisa são apresentadas no Quadro 2.

Quadro 2 - Categorias analítico-empíricas e variáveis correspondentes.

\section{Categorias analítico-empíricas}

Agentes externos: conjunto dos elementos externos ao processo de planejamento estratégico de cada organização investigada com influência direta sobre o aludido processo.

Campo organizacional: conjunto de organizações similares e diferentes, porém interdependentes, atuando em uma área reconhecida da vida institucional, que compartilham sistemas de significados entre si e que se inter-relacionam a partir da dinâmica da realocação de recursos de poder e da posição relativa em relação aos outros atores do campo (MACHADO-DA-SILVA et al., 2006).

Fonte: elaborada pelos autores (2012).
Organizacionais: agentes externos cujas natureza constitutiva e forma de interferência sejam organizacionais.

Consultor: profissional reconhecido e qualificado que desenvolve prestação de serviço para um determinado cliente (individual ou organizacional).

Valores predominantes: conjunto das premissas, princípios, crenças e práticas simbólicas que predominam no campo das organizações estudadas.

Relações inter-organizacionais: contatos, trocas e interesses recorrentes que se verificam entre organizações, segundo lógica de coordenação. 
As interfaces entre estratégia e ambiente institucional de referência: o caso do Tribunal Regional Eleitoral de Santa Catarina (TRESC)

Os dados coletados, à luz dos pressupostos teóricos e das categorias analítico-empíricas, foram expostos ao tratamento da análise documental, da análise de conteúdo (BARDIN, 1977) e da triangulação de dados. Procurou-se, ante a natureza do fenômeno investigado, identificar sua carga simbólica substancial, extraindo o conteúdo latente e não apenas aquele manifesto.

Pela técnica da triangulação de dados, compararam-se os dados obtidos nas análises das entrevistas realizadas e dos documentos consultados, objetivando identificar padrões convergentes entre os resultados obtidos (FLICK, 2009).

Como limitação do estudo, pontuase a escolha das categorias e variáveis analítico-empíricas, que restringem a amplitude e o conteúdo das constatações obtidas - a escolha foi delimitada pelo critério da viabilidade de realização do estudo.

\section{Análise e discussão do caso}

A Justiça Eleitoral contemporânea é formação político-institucional derivada da Constituição Federal de 1988, sendo formada pelo Tribunal Superior Eleitoral (TSE), com sede em Brasília, por Tribunais Regionais Eleitorais, um em cada unidade da federação, com sede em capitais de Estado, e pelos juízes e juntas eleitorais, que atuam em zonas eleitorais. A organização investigada - TRESC -, é composta por 105 (cento e cinco) zonas eleitorais.

O campo organizacional da Justiça Eleitoral, composto, assim, por 27 (vinte e sete) tribunais regionais (TRE) e pelo Tribunal Superior Eleitoral (TSE), tem formação consentânea à evolução política e administrativa do Brasil, não sendo decorrente apenas do ordenamento constitucional e infraconstitucional vigente, mas também da complexa e retalhada evolução política e social que conformou a atual sociedade brasileira. Sua representação pode ser visualizada pela Figura 1.

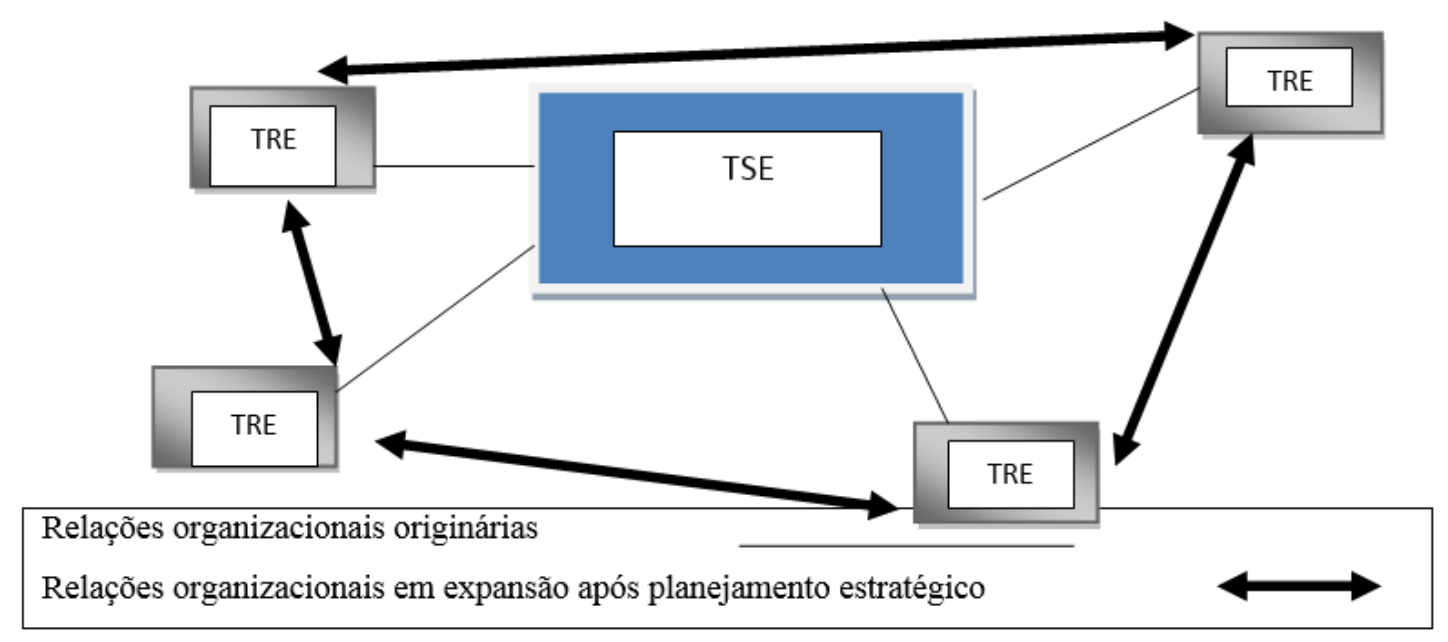

Figura 1 - Campo organizacional da Justiça Eleitoral Fonte: elaborada pelos autores (2013).

Em especial, caracteriza-se pela: (a) forte tradição hierárquica e de rigidez formal, consequiência do ordenamento jurídico a que está submetido; (b) foco periódico, improrrogável e privativo - realizar eleições - prioritário a qualquer outra ati- vidade administrativa; (c) composição de seus quadros diretivos, temporários e oriundos dos outros órgãos do Poder Judiciário (ministros do Supremo Tribunal Federal, desembargadores de Tribunais de Justiça e juízes de direito); (d) natureza execu- 
tiva de suas atribuições, pois além de ser responsável por sua gestão, incumbe-se da administração de eleições.

No que toca à discussão dos resultados propriamente dita, destaca-se que a categoria analítico-empírica agentes externos foi decomposta, conforme evidenciado nos procedimentos metodológicos, nas variáveis agentes externos organizacionais e consultor. No que toca à categoria agentes externos, a partir de leituras exploratórias, de observações do pesquisador, das entrevistas realizadas e dos questionários aplicados, identificaram-se duas organizações com papel interveniente sobre os planejamentos estratégicos investigados: o Conselho Nacional de Justiça (CNJ) e o Tribunal Superior Eleitoral.

Um dos entrevistados destacou as "imposições externas" a partir de objetivos e indicadores estratégicos nacionais por parte do CNJ, com coordenação e direcionamento do TSE no âmbito da Justiça Eleitoral e, em outra entrevista, ressaltou-se a atuação do TSE como elemento incentivador das práticas de planejamento estratégico.

O CNJ, órgão do Poder Judiciário responsável pela reformulação de quadros e meios do Judiciário, sobretudo no que diz respeito ao controle e à transparência administrativa e processual (CNJ, 2009), foi criado em dezembro de 2004, por força da Emenda Constitucional n. 45/2004, e instalado oficialmente em junho de 2005. Sua atuação sobre o planejamento e a gestão estratégica no âmbito do Poder Judiciário aflorou em março de 2009, com o advento da Resolução CNJ n. 70/2009.

Neste dispositivo, tal conselho instituiu o Planejamento Estratégico do Poder Judiciário, com a definição de missão, visão, valores e objetivos estratégicos daquele Poder de Estado; e determinou, ainda, que todos os tribunais brasileiros, dentre os quais os tribunais regionais eleitorais, elaborassem os seus respectivos planejamentos estratégicos, convergentes ao Plano
Estratégico Nacional, abrangendo espaço temporal mínimo de 5 (cinco) anos.

Os dois agentes externos organizacionais - CNJ e TSE -, representam, assim, atores estruturantes do isomorfismo estratégico no contexto do campo organizacional da Justiça Eleitoral, seja pela forte atuação coercitiva do $\mathrm{CNJ}$, com a autoridade decorrente do ordenamento constitucional, seja sob o papel de dominância do TSE no campo organizacional investigado, sob a ótica político-institucional.

Quanto à variável consultor, a opção pelos serviços de consultoria teve, conforme entrevistas efetuadas, como fundamento: (a) a ausência de servidor com competência técnica na área de gestão estratégica; (b) o caráter neutro de um elemento externo, desligado, na expressão utilizada por um dos entrevistados, dos "feudos" existentes na organização; (c) a legitimidade e o reconhecimento imputáveis ao consultor como profissional reconhecido pelo mercado.

O consultor, como elemento de facilitação, exerceu um importante papel isomórfico: o de método. Diante do desconhecimento organizacional na área de gestão estratégica, o consultor, usando de sua experiência acadêmica, de cases de sucesso e de experiências práticas em outras organizações, propôs e desenvolveu uma estrutura metodológica de planejamento estratégico objeto de aplicação em outras organizações. O método, como caminho a ser traçado, delimita esforços e restringe a visão estratégica. Seu potencial isomórfico merece ser relevado.

$\mathrm{O}$ isomorfismo metodológico, que contribui para um isomorfismo estratégico, pode ser representado, na organização estudada, pelos seguintes elementos: (a) Bases Estratégicas Corporativas (BEC), contemplando missão, visão e valores institucionais; (b) ciclo objetivos institucionais/estratégias/ações estratégicas/definição de metas e indicadores de desempenho; (c) uso de técnica SWOT para diagnóstico organizacional e ambiental; (d) uso 
da metodologia denominada Balanced Score Card (BSC), resultando na construção de um mapa estratégico, contendo objetivos que, decompostos, atrelam-se a metas e indicadores de desempenho.

A categoria analítico-empírica campo organizacional, por sua vez, foi especificada em duas variáveis - valores predominantes e relações interorganizacionais -, que serão analisadas de maneira encadeada.

Em termos de estruturação do campo, há forte interação TSE-TRE. As relações entre TRE ocorrem, quando muito, de forma esparsa e pontual ou, o que é rotineiro, com a participação do TSE, em grupos de trabalho contendo representantes dos tribunais regionais. Cada tribunal regional, inobstante possuir estrutura organizacional e recursos orçamentários próprios, submete-se à autoridade do TSE no que toca às diretrizes institucionais e orçamentárias.

Neste sentido, o tribunal superior exerce papel de dominância, pois a ele compete a ratificação (ou não) e o encaminhamento da proposta orçamentária de cada regional, reunidas no Orçamento da Justiça Eleitoral, ao Congresso Nacional. Disto, suscita-se a dinâmica do campo organizacional estudado como arena de poder e conflito, visto que o tamanho do orçamento de cada regional é diretamente proporcional à conformidade e visibilidade aos desejos do TSE.

Essa dominância do TSE no interior do campo organizacional foi fortalecida pela atuação do Conselho Nacional de Justiça (CNJ), que instituiu o Plano Estratégico Nacional do Poder Judiciário, que prevê a garantia do alinhamento estratégico em todas as unidades do Judiciário, materializado no caso da organização estudada através do planejamento estratégico, sob a coordenação nacional do TSE.

Em busca de recursos técnicos (orçamento) e institucionais (reconhecimento e legitimidade), os tribunais regionais buscam implementar aquelas práticas reconhecidas pelas estruturas de dominação existentes no campo (no caso da Justiça
Eleitoral, o TSE). No anseio de buscar incremento no apoio político-institucional do TSE, que se traduzirá em maiores receitas orçamentárias, cada tribunal regional busca o desenvolvimento de programas, práticas e projetos, dentro das intenções e diretrizes do tribunal superior, que o alcem à categoria de organização reconhecida dentro do campo organizacional.

A diretriz institucional dominante no campo organizacional, defendida pelo TSE diante do reconhecimento e legitimidade popular obtidos por sua adoção, é uma visão instrumental de Justiça Eleitoral, representada pela eficiência operacional na realização das eleições. A urna eletrônica trouxe eficiência e celeridade à operacionalização de uma eleição, além de revesti-la de segurança e transparência.

As eleições, nesse sentido, representam a "vitrine eleitoral", por meio da qual a Justiça Eleitoral demonstra sua existência e atuação. A avaliação social dessa justiça especializada é centrada na transparência, eficiência do pleito e, especialmente, na celeridade da divulgação do seu resultado ${ }^{\text {iii }}$. Nada mais demonstrativo, neste entendimento, do que as colocações do então Ministro-Presidente do TSE no Ofício-Circular n. 4.766/2008/GDG, dirigido aos Presidentes dos Regionais Eleitorais, em que há endosso acerca da execução dos procedimentos de segurança na manipulação das urnas eletrônicas: "em sentido figurado, as urnas são o palco a que ascende o eleitor-cidadão para, por meio do voto, exercer a soberania popular" (grifei).

Essa concepção instrumental representa a busca por legitimidade institucional do campo organizacional da Justiça Eleitoral perante a sociedade brasileira, e, nesse sentido, condiciona a própria atuação e consolidação institucional do campo e das organizações em particular. Nas discussões levadas a cabo pela Equipe Gestora do Planejamento Estratégico no TRESC, aventou-se, neste sentido, um duplo caminho a ser trilhado pela Justiça Eleitoral, cujas alternativas foram interpretadas como mutuamente exclusivas: ou a concen- 
tração em competência técnicoinstrumental, definindo o negócio institucional como a realização eficaz, eficiente e efetiva de eleições, ou o desenvolvimento da atuação na conscientização política da sociedade, seja por intermédio de campanhas educativas ou mediante a participação em processos deliberativos e dialógicos que fogem ao âmbito político-eleitoral, como as práticas de orçamento participativo.

A concentração na competência técnico-instrumental, com o foco nas eleições e centralização nos processos tecnológicos de registro, apuração e totalização dos votos, foi o direcionamento estratégico escolhido, em consonância com os valores predominantes no campo organizacional. A atuação na conscientização política foi eleita como valor organizacional; não obstante, membros da equipe diretiva (entrevistas e relatos esparsos) consideraram-no um valor marginal, que terá pouco apoio e comprometimento da administração, de difícil operacionalização e divergente da visão de Justiça Eleitoral construída no contexto no direcionamento estratégico adotado.

Tal direcionamento, ademais, encampa a necessidade de incutir na sociedade uma visão positiva do desempenho institucional, ao relacioná-lo com o paradigma social dominante acerca da gestão empresarial: célere, eficaz, eficiente e flexível. Essa relação, como já mencionado anteriormente, dá-se de forma ampla pela realização eficiente das eleições mediante o uso de uma tecnologia específica - a urna eletrônica -, mas, em particular, pela adoção da prática do planejamento estratégico.

O planejamento estratégico, como prática formal de estratégia, representa uma demonstração manifesta e facilmente identificada, controlada e avaliada de gestão do futuro das organizações. Essa "demonstração mensurável" traduz-se em dupla tentativa de legitimação: no plano interno da organização, "onde a adoção de mecanismos formais vinculados às concepções de agentes organizacionaischaves, como o nível dirigente, permite melhor aceitação de decisões e medidas específicas" (MACHADO-DA-SILVA; VIZEU, 2007, p. 92); no plano externo da organização, transmitindo aos depositários da legitimidade a imagem de que a organização está concatenada com a modernidade gerencial, adotando técnicas e processos de "vanguarda".

No ambiente institucional de referência, a lógica de ação envolveu a procura por legitimidade, aceitação e credibilidade junto ao campo organizacional e à sociedade tomada lato sensu. Nesse sentido, a organização analisada desenvolveu práticas, estruturas e processos institucionalmente aceitos pelos depositários da legitimidade, como consequência: (a) do anseio em alinhavar os interesses da sociedade com os interesses interna corporis organizacionais, em especial a estrutura de autoridade vigente na organização; e (b) da estabilidade das estruturas de dominação e padrões de coalizão inter-organizacionais definidos.

Todavia, esse direcionamento estratégico condicionado pelo ambiente institucional de referência, assentado na busca de legitimidade e, nesse sentido, coerente com as normas e valores predominantes no campo organizacional, ao garantir a estabilidade da organização no horizonte temporal próximo, pode acabar limitando as escolhas estratégicas de longo prazo, especialmente quando vão de encontro com a busca de legitimidade institucional, isto é, com a manutenção da sobrevivência atual das organizações que compõem o ambiente institucional de referência.

No caso da organização analisada e do campo organizacional no qual se insere, o ambiente institucional moldou as escolhas estratégicas, que convergiram para a realização do processo eleitoral e para as ações que subsidiam sua 
instrumentalização. Fatores como a avaliação social positiva, o know-how acumulado, o poder concentrado pela lógica dominante na organização investigada, ligada à área jurídica e de tecnologia da informação, e a necessidade de manutenção de uma imagem de instituição eficiente e célere, valores atrelados à urna eletrônica e à eleição informatizada, contribuíram para a construção da direção estratégica tomada e, no conjunto, representam os elementos institucionais delimitadores da estratégica da organização investigada.

A direção estratégica perseguida acabou por desconsiderar ou conceder importância menor ao desenvolvimento da atuação na conscientização política da sociedade e, especialmente, nos processos deliberativos e dialógicos que fogem ao âmbito político-eleitoral, como as práticas de orçamento participativo, ou dos que surgem no âmbito da própria sociedade civil.

Com isso, a Justiça Eleitoral, como um todo, e a organização investigada, em particular, descuram-se de dois aspectos que cada vez mais ganham corpo no mundo social. Primeiro, a existência de uma esfera pública, "renovação mais importante na teoria democrática da segunda metade do século XX" (AVRITZER, 1994, p. 29), "[...] espaço intersubjetivo, comunicativo, no qual as pessoas tematizam suas inquietações por meio do entendimento mútuo" (TENÓRIO, 2008, p. 41), onde os problemas que afetam o conjunto da sociedade são recepcionados, discutidos e tematizados (FARIA, 2000), espaço possível e concreto de comunicação e de deliberação entre sociedade, Estado e capital. $\mathrm{Na}$ realidade brasileira, em particular, essa esfera pública vem se constituindo num novo espaço público, "[...] onde irão situar-se conselhos, fóruns, redes e articulações entre a sociedade civil e representantes do poder público" (GOHN, 2004).

Segundo, a construção de uma democracia dialógica e participativa, originada dos movimentos sociais que colocam em questão as práticas sociais excludentes e, em contrapartida, reivindicam e, ao mesmo tempo, constituem formas de controle e de exercício do governo pelos próprios cidadãos, cada vez menos representativas e mais participativas, num resgate das tradições democráticas mais remotas. Tal democracia tem crescentemente representado, sob o ponto de vista político e social, um dos principais fenômenos a partir dos quais a emancipação social está sendo remodelada (SANTOS, 2002).

A democracia participativa, na visão de Santos e Avritzer (2003), mantém relação de coexistência e complementaridade com a democracia procedimental e representativa, ligada ao processo eleitoral, direção estratégica adotada pelo campo organizacional da Justiça Eleitoral e, em consequência, pela organização analisada. Os aludidos autores, ao projetarem o potencial dessa forma de democracia, apontam para a tendência do fortalecimento, no campo político e social, da demodiversidade, isto é, da coexistência pacífica ou não conflituosa entre diferentes modelos ou práticas democráticas, e da ampliação do experimentalismo democrático, ou seja, do surgimento de novas formas de modelos e processos democráticos conformes ao entorno envolvente, articulados, em perspectiva mais ampla, ao âmbito global.

A organização investigada e o campo organizacional do qual faz parte, ao conformar-se ao ambiente institucional de referência, a partir dos mecanismos isomórficos ali presentes, deixou de construir sua direção estratégica em convergência com os desdobramentos e inovações que surgem das práticas sóciopolíticas da atualidade e que, crescentemente, passam a receber a atenção da teoria política e sociológica modernas, como, em especial, constatou-se quanto à existência de esferas públicas e à consolidação de modelos de democracia 
participativa, marcados pela acentuada diversidade e experimentalismo nos modelos, práticas e processos.

Desta feita, os elementos institucionais presentes no campo da organização em tela, ao preservarem a sobrevivência da organização num horizonte temporal próximo, podem dificultar a adaptabilidade e as mudanças necessárias no longo prazo, visto que a visão de futuro percebida do processo estratégico é conservadora, voltada à busca de legitimidade e, portanto, à conformidade. A própria capacidade de agência da organização, embora não negada, é em muito restrita e moldada à interpretação do ambiente institucional de referência.

\section{Considerações finais}

O presente artigo, inserindo-se no contexto de alargamento das investigações empíricas sobre o novo institucionalismo sociológico, tratou da interface entre as transações da organização com o ambiente e as respectivas estratégias delineadas. A partir do exame da influência do ambiente institucional de referência no direcionamento estratégico do Tribunal Regional Eleitoral de Santa Catarina (TRESC), instituição pertencente ao campo organizacional da Justiça Eleitoral, percebeu-se que a lógica de ação envolveu a procura por legitimidade, aceitação e credibilidade junto ao campo organizacional e à sociedade tomada lato sensu.

Como consequência direta, a organização analisada desenvolveu práticas, estruturas e processos institucionalmente aceitos pelos depositários da legitimidade, em decorrência: (a) do anseio em alinhavar os interesses da sociedade com os interesses interna corporis organizacionais, em especial a estrutura de autoridade vigente na organização; e (b) da estabilidade das estruturas de dominação e padrões de coalizão inter-organizacionais definidos.
Tal lógica de ação materializou-se na concentração em competência técnicoinstrumental, com o foco nas eleições e centralização nos processos tecnológicos de registro, apuração e totalização dos votos. Esse direcionamento, ademais, encampa a necessidade de incutir na sociedade uma visão positiva do desempenho institucional, ao relacioná-lo com o paradigma social dominante acerca da gestão empresarial: célere, eficaz, eficiente e flexível.

Todavia, os elementos institucionais presentes no campo da organização em tela, ao preservarem a sobrevivência da organização num horizonte temporal próximo, restringem a adaptabilidade e as mudanças necessárias no longo prazo, visto que a visão de futuro percebida do processo estratégico, a partir da interpretação do ambiente institucional, é conservadora. Com isso, a conscientização política da sociedade e, especialmente, a atuação nos processos deliberativos e dialógicos que fogem ao âmbito políticoeleitoral, como as práticas de orçamento participativo, ou dos que surgem no âmbito da própria sociedade civil, tiveram importância minimizada durante a construção do processo estratégico.

Visto de outra forma, as tendências percebidas no campo político e social, como a democracia participativa, a diversidade democrática, o experimentalismo democrático e consolidação de esferas públicas foram desconsideradas em detrimento da atuação já consolidada no processo eleitoral formal, com formato, tempo, prazo e atores previsivelmente conhecidos.

Para a organização investigada, a relevância do presente estudo residiu na possibilidade de refletir acerca de suas escolhas estratégicas de longo prazo, permitindo a aproximação frente às tendências sociais e democráticas já existentes na realidade social e que se fortalecerão num futuro próximo, bem como na oportunidade de adotar decisões 
As interfaces entre estratégia e ambiente institucional de referência: o caso do Tribunal Regional Eleitoral de Santa Catarina (TRESC)

gerenciais mais coerentes com os clamores sociais da aplicação eficiente dos recursos públicos e da prestação otimizada de serviços demandados pela coletividade, em relação de aproximação entre Estado e sociedade civil, na qual a preocupação primária deixe de estar voltada à manutenção da estrutura burocrática.

Do ponto de vista acadêmico, o estudo representou esforço de alargamento das investigações empíricas que adotam a abordagem institucionalista nos estudos organizacionais, trazendo, ademais, reflexões acerca da relação entre ambiente e estratégia organizacional.

\section{Referências}

AMBONI, N. Base estratégica corporativa. Revista Brasileira de Administração, Brasília, v. 37, n. 37, p. 8-16, 2002.

AVRITZER, L. Teoria democrática, esfera pública e participação. Sociologias, Porto Alegre, n. 2, jul./dez. 1994, p. 18-43.

BARDIN, L. Análise de conteúdo. Lisboa: Edições 70, 1977.

BERGER; P. L.; LUCKMANN, T. A construção social da realidade: tratado de sociologia do conhecimento. Petrópolis: Vozes, 2009.

CARVALHO, C. A.; VIEIRA, M. M. F.; LOPES, F. D. Contribuições da perspectiva institucional para análise das organizações. In: XXIII ENANPAD Encontro Anual da Associação Nacional dos Programas de Pós-Graduação em Administração, 1999, Foz do Iguaçu. Anais... Foz do Iguaçu: ANPAD, 1999.

A transformação organizacional das ONGs no Brasil: um processo de isomorfismo com as ONGs do norte. In: I EnEO Encontro Nacional de Estudos Organizacionais, 2000, Curitiba. Anais... Curitiba: ANPAD, 2000.
; VIEIRA, M. M. F.; GOULART, S. A trajetória conservadora da teoria institucional. Revista de Administração Pública, Rio de Janeiro, v. 39, n. 4, p. 849874, jul./ago. 2005.

CLEGG, S. R. As organizações modernas. Oeiras: Celta, 1998.

CONSELHO NACIONAL DE JUSTIÇA (CNJ). A estratégia do Poder Judiciário. Brasília: 2009.

CRUBELlATE, J. M.; GRAVE, P. S.; MENDES, A. A. A questão institucional e suas implicações para o pensamento estratégico. Revista de Administração Contemporânea, Curitiba, v. 8, edição especial, p. 37-60, 2004.

DAFT, R. L. Organizações: teoria e projetos. São Paulo: Thomson, 2006.

DIMAGGIO, P. J.; POWELL, W. W. Introduction. In: POWELL, W. W.; DIMAGGIO, P. J. (orgs.), The new institutionalism in organizational analysis. Chicago: The University of Chicago Press, p. 1-38, 1991.

A gaiola de ferro revisitada: isomorfismo institucional e racionalidade coletiva nos campos organizacionais. Revista de Administração de Empresas, São Paulo, v. 45, n. 2, p. 74-89, abr./jun. 2005.

FARIA, C. F. Democracia deliberativa: Habermas, Cohen e Bohman. Lua Nova, São Paulo, n. 49, 2000, p. 47-68.

FONSECA, V. S. da. A abordagem institucional nos estudos organizacionais: bases conceituais e desenvolvimentos contemporâneos. In: VIEIRA; M. M. F.; CARVALHO, C. A. (Org.). Organizações, instituições e poder no Brasil. Rio de Janeiro: FGV, p. 47-63, 2003.

FLICK, U. Introdução à pesquisa qualitativa. Porto Alegre, Bookman, 2009.

GIMENEZ, F. A. P. JÚNIOR, P. H.; GRAVE, P. S. Isomorfismo mimético em estratégia: uma ferramenta para 
investigação. Revista de Administração Mackenzie, São Paulo, v. 8, n. 4, p. 35-59, 2007.

GOHN, M. da G. Empoderamento e participação da comunidade em políticas sociais. Saúde e Sociedade, São Paulo, v. 13, n. 2, maio/ago. 2004, p. 20-31.

HAFSI, T.; MARTINET, A.-C. Estratégia e gestão estratégica das empresas: um olhar histórico e crítico. Revista de Administração Contemporânea, Curitiba, v. 12, n. 4, p. 1131-1158, out./dez. 2008.

HALL, P. A.; TAYLOR, R. C. R. As três versões do neo-institucionalismo. Lua Nova Revista de Cultura e Política, São Paulo, v. 58, n. 1, p. 193-223, 2003.

KIRSCHBAUM, C.; CRUBELLATE, J. M. As várias institucionalizações da teoria neo-institucional. Revista de Administração de Empresas, São Paulo, vol. 49, n. 1, p. 108-109, jan./mar. 2009.

MACHADO-DA-SILVA, C. L.; BARBOSA, S. de L. Estratégia, fatores de competitividade e contexto de referência das organizações: uma análise arquétipa. Revista de Administração Contemporânea, Curitiba, v. 6, n. 3, p. 732, set./dez. 2002.

et al. Institucionalização da mudança na sociedade brasileira: o papel do formalismo. In: VIEIRA; M. M. F.; CARVALHO, C. A. (Org.). Organizações, instituições e poder no Brasil. Rio de Janeiro: FGV, 2003, p. 179-202.

; FONSECA, V. S. da. Conversação entre abordagens da estratégia em organizações: escolha estratégica, cognição e instituição. Organizações \& Sociedade, Salvador, v. 9, n. 25, p. 93-109, set./dez. 2002.

; __ ; FERNANDES, B. H. R.

Mudança e estratégia nas organizações: perspectivas cognitiva e institucional. In: XXII ENANPAD Encontro Anual da As- sociação Nacional dos Programas de PósGraduação em Administração, 1998, Foz do Iguaçu. Anais... Foz do Iguaçu: ANPAD, 1998.

; GONÇALVES, S. A. Nota técnica: a teoria institucional. In: CALDAS, M. P.; FACHIN, R.; FISCHER, T. (Org.). Handbook de estudos organizacionais. São Paulo: Atlas, 2004, v. 1, p. $218-225$.

; GUARIDO FILHO, E. R.; ROSSONI, L. Campos organizacionais: seis diferentes leituras e a perspectiva de estruturação. Revista de Administração Contemporânea, Curitiba, v. 10, edição especial, 159-196, 2006.

MACHADO-DA-SILVA, C. L.; VIZEU, F. Análise institucional de práticas formais de estratégia. Revista de Administração de Empresas, São Paulo, v. 47, n. 4, p. 89100, out./dez. 2007.

MEYER, J.; ROWAN, B. Institutionalized organizations: formal structure as yth and ceremony. American Journal of Sociology, 1977.

; SCOTT, W. R. Centralization and legitimacy problems of local government. In: MEYER, J. W.; SCOTT, W. R. Organizational environments: ritual and rationally. London: Sage Publications, 1983.

MOTTA, F. C. P.; VASCONCELOS, I. F. F. G. de. Teoria Geral de Administração. São Paulo: Pioneira Thomson Learning, 2002.

PACHECO, F. L. O ambiente institucional como agente de mudança: o caso do teatro Apolo-Hermilo. In: XXV Encontro Nacional de Pós-Graduação em Administração, 2001, Campinas. Anais... Campinas: ANPAD, 2001.

PECI, A. A nova teoria institucional em estudos organizacionais: uma abordagem crítica. Cadernos Ebape.br (online), Rio de Janeiro, v. 4, n. 1, p. 1-12, mar. 2006. Disponível em: 
As interfaces entre estratégia e ambiente institucional de referência: o caso do Tribunal Regional Eleitoral de Santa Catarina (TRESC)

<www.ebape.fgv.br/cadernosebape>.

Acesso em: 24 ago. 2009.

SANTOS, B. de S. Democracia e participação. Porto: Afrontamento, 2002.

; AVRITZER, L. Para ampliar o cânone democrático. In: SANTOS, B. de S. (Org.). Democratizar a democracia: os caminhos da democracia participativa. 2 . ed. Rio de Janeiro: Civilização Brasileira, 2003, p. 1-26.

SCOTT, W. R. The organization of environments: network, cultural and historical elements. In: MEYER, J. W.; SCOTT, W. R. Organizational environments: ritual and rationality. London: Sage Publications, 1992.

SILVA, R. C. da; OLIVEIRA, R. P. Instituições e conflitos no campo dos museus de Santa Catarina. Cadernos Ebape.br (online), Rio de Janeiro, v. 6, n. 3, p. 1-16, set. 2008. Disponível em: <www.eba pe.fgv.br/cadernosebape>. Acesso em: 10 ago. 2009.

STAKE, R. Qualitative Case Studies. In: DENZIN, N. K.; LINCOLN, Y.S. (Eds.). The sage handbook of qualitative research. 3. ed. London: Sage, 2005, p. 443-466.

TENÓRIO, F. G. (Re)visitando o conceito de gestão social. In: SILVA JR. et al (Orgs.). Gestão social: práticas em debate, teorias em construção. Juazeiro do Norte: UFC, 2008.

THÉRET, B. As instituições entre as estruturas e as ações. Lua Nova Revista de Cultura e Política, São Paulo, v. 58, n. 1, p. 225-254, 2003.

TRIBUNAL REGIONAL ELEITORAL DE SANTA CATARINA (TRESC). Base estratégica corporativa. Florianópolis: 2008.

VASCONCELOS, F. C. de. A institucionalização das estratégias de negócios: o caso das start-ups na internet brasileira em uma perspectiva construtivista. Revista de
Curitiba, v. 8, n. 2, p. 159-179, abr./jun. 2004.

VIEIRA, M. M. F; CARVALHO, C. A. (Orgs.). Organizações, instituições e poder no Brasil. Rio de Janeiro: FGV, 2003.

ZUCKER, L. G.; TOLBERT, P. S. A institucionalização da teoria institucional. In: CALDAS, M. P.; FACHIN, R.; FISCHER, T. (Org.). Handbook de estudos organizacionais. São Paulo: Atlas, 2004, v. 1, p. 194-217.

\footnotetext{
' Por abordagem institucional nos estudos organizacionais, toma-se como referência o institucionalismo sociológico, vertente mais representativa, muito embora não a única presente nos estudos organizacionais. Para uma compreensão das orientações ou versões da teoria institucional moderna, ver Hall e Taylor (2003) e Théret (2003).

ii Separação entre estruturas formais e práticas organizacionais; entre teoria das organizações e prática (KIRSCHBAUM; CRUBELLATE, 2009; MOTTA; VASCONCELOS, 2002).

iii Segundo pesquisa realizada em 2006 pelo Instituto Nexus, a pedido da Fundação Padre Anchieta/TV Cultura, a Justiça Eleitoral teve avaliação positiva de $88,7 \%$ dos entrevistados; $88 \%$ deles confiam no resultado das eleições; $76,3 \%$ vêem-na como eficiente e $87,9 \%$ consideram-na ágil na apuração dos votos
}

Administração Contemporânea, 